\title{
The Challenges of Insider Research in Educational Institutions: Wielding a double-edged sword and resolving delicate dilemmas
}

By Dr. Justine Mercer,

\section{Centre for Educational Leadership and Management, University of Leicester.}

\begin{abstract}
This paper explores the challenges faced by educational researchers investigating the places where they work. It reviews the literature on insider research and draws upon the author's own experience of researching faculty appraisal at two Higher Education institutions where she taught. It argues that the insider/outsider dichotomy is actually a continuum with multiple dimensions, and that all researchers constantly move back and forth along a number of axes, depending upon time, location, participants and topic. The assumption that one kind of research is better than the other is challenged, and the advantages and disadvantages of insider research are discussed in terms of access, intrusiveness, familiarity and rapport. Finally, three dilemmas relating to informant bias, reciprocity in interviews, and research ethics are examined from an insider researcher's perspective, and the ways in which the author responded to these dilemmas at different points in her own four-year two-site study are critiqued.
\end{abstract}

\section{Introduction}

This paper results from my own four-year study into systems of faculty appraisal at two Higher Education institutions (HEIs) in the Middle East where I worked as a lecturer. Whilst the research generated some substantive findings about the management of HEIs, it also caused me to reflect upon the process of conducting insider research, and to examine how the varying levels of insiderness I experienced 
at each of my two research sites affected the choices I made regarding how much to reveal to colleagues about myself and my research. Naturally, these choices are not presented as examples of 'best practice', but, since I conducted insider research with the same focus (appraisal), approach (case study) and methods (participant observation and interviews), at two very similar sites, I would like to think my reflections on the process provide an opportunity for further debate of a methodological issue that is under-researched, yet crucial to an ever-increasing number of educational researchers.

The last twenty years have seen an exponential rise in the amount of small-scale practitioner research in education, as evidenced by the great proliferation of Masters and Doctoral programmes now being offered by Schools of Education, around the world, and the corresponding increase in student numbers. The emergence of the Doctorate in Education (Ed.D), as distinct from the Doctorate in Philosophy (Ph.D) can be interpreted as both a stimulus and a response to this trend. The great majority of students complete these courses on a part-time basis whilst continuing with their regular jobs, with the result that their own school or college often becomes their research site. Given that so many people are now engaged in this kind of research, one might have expected a corresponding growth in the literature on the methodology of insider research in educational contexts. This does not appear to be the case.

Certainly, a great deal has been written about educational action research, including Schon's (1983) seminal book, The Reflective Practitioner, and work by Carr and Kemmis (1983), Kemmis (1993), and Lomax (2002), to name but a few. Similarly, much has been written about the insider/outsider debate in contexts other than 
education. These include studies from the fields of anthropology (Aguilar, 1981; Narayan, 1993; Ohnuki-Tierney, 1984), ethnic studies (Beoku-Betts, 1994; Wilson, 1974; Zinn, 1979); family research (Christensen and Dahl, 1997; Olson, 1977; Surra and Ridley, 1991); feminist studies (DeVault, 1996; Finch, 1984; Reay, 1995; Reissman, 1987); geography (Mullings, 1999); management (Cassell, 2005); nursing (Carter, 2004); social work (Kanuha, 2000) and sociology (Griffith, 1998; Merton, 1972). Rather less, however, has been published specifically about 'the unique epistemological, methodological, political, and ethical dilemmas' (Anderson and Jones, 2000, p. 430) facing educationalists researching the management of their own institutions. Four such studies are cited below, the first by Preedy and Riches (1988) describing the topics chosen by teachers undertaking an Open University course in school management; the second by Anderson and Jones (2000) reporting on 50 doctoral dissertations completed by 'administrator researcher'; the third by Hockey (1993) surveying the literature on researching peers and familiar settings; and the fourth by Labaree (2002) described his own experience of researching shared governance at the university where he worked.

Thus, the literature in this area could hardly be described as extensive. Indeed, traditional textbooks on research methodology, in education generally, and in educational leadership, more specifically, tend to gloss over the intricacies of insider research conducted at one's place of work, and researchers in such a position are not well-supported in their attempts to navigate the 'hidden ethical and methodological dilemmas of insiderness' (Labaree, 2002, p. 109). 
The purpose of this paper, therefore, is, firstly, to discuss the underlying issues, with reference to appropriate literature, in order to help insider researchers better analyze their own position, and, secondly, to provide specific examples of the situations I faced and the choices I made, during the four years I taught at two HE institutions, whilst simultaneously researching their systems of faculty appraisal.

This article is divided into three parts. Part one examines the concept of insiderness, tracing its history through the twentieth century, and arguing that insiderness and outsiderness are better understood in terms of a continuum rather than a dichotomy. Part two discusses 'the distinctive assets and liabilities' (Merton, 1972, p. 33) of insider research, arguing that what is lost on the swings is more than compensated for on the roundabouts. Part three describes three specific insider dilemmas, relating to informant bias, interview reciprocity and research ethics, and explains the ways in which these dilemmas were approached at different points during the course of my own four-year study into faculty appraisal.

\section{Part 1: The Concept of Insiderness}

In the first half of the twentieth century, a number of white anthropologists researched 'natives', living in exotic locations, such as Melanesian New Guinea (Malinowski, 1922) and Samoa (Mead, 1929). The differences between the researcher and the researched were so seemingly obvious that it was considered easy to draw a distinction between the stranger and the native. In the second half of the twentieth century, anthropologists and sociologists began to study not the strange but the familiar, 'in terms of their own culture, gender, religions, residential and ethnic 
backgrounds' (Hockey, 1993, p. 201). Thus, a new distinction emerged, between the insider and the outsider, based upon the idea that particular groups have 'monolithic' or, at least, 'privileged' access to particular kinds of knowledge (Merton, 1972, p. 11). 'In this conception, Insiders are the members of specified groups and collectivities, or occupants of specified social statuses. Outsiders are the nonmembers' (Merton, 1972, p. 21). The insider is 'someone whose biography (gender, race, class, sexual orientation and so on) gives her [sic] a lived familiarity with the group being researched' while the outsider is 'a researcher who does not have any intimate knowledge of the group being researched, prior to entry into the group' (Griffith, 1998, p. 361).

Whilst the distinction between the stranger and the native was relatively clear-cut, the distinction between the outsider and the insider is not quite so obvious. It could be argued that the researcher who shares a particular characteristic, for example gender, ethnicity or culture, with the researched is an insider, and everyone else, not sharing that particular characteristic, is an outsider. On this basis, the insider and outsider perspectives are 'two mutually exclusive frames of reference' (Olson, 1977, p. 171).

It could also be argued, however, that 'individuals have not a single status, but a status set' (Merton, 1972, p. 22) and that identities are 'always relative, cross cut by other differences and often situational and contingent' DeVault (1996, p. 35). For this reason, a great many authors, including Anderson and Jones (2000), Bulmer (1982), Carter (2004), Hockey (1993), Kelleher and Hillier (1996), Labaree (2002), Narayan (1993) and Surra and Ridley (1991), reject the insider/outsider dichotomy proposed by Olson (1977) in favour of a continuum, with the two abstractions better considered 
as end points 'existing in conceptualization rather than fact' (Christensen and Dahl, 1997, p. 282). The boundaries between the two are both 'permeable' (Merton, 1972, p. 37) and 'highly unstable' (Mullings, 1999, p. 338), with the result that we are all 'multiple insiders and outsiders' (Deutsch, 1981, p. 174), moving 'back and forth across different boundaries' (Griffith, 1998, p. 368), 'as situations involving different values arise, different statuses are activated and the lines of separation shift' (Merton, 1972, p. 28).

Some features of the researcher's identity, such as his or her gender, ethnicity and sexual orientation are innate and unchanging; other features, such as age, are innate but evolving. These features provide one dimension to the insider/outsider continuum. Other dimensions are provided by the time and place of the research (at both a micro and a macro-level); the power relationships within which the researcher and the researched co-exist; the personalities of the researcher and specific informants; and even the precise topic under discussion.

In my own study, for example, I engaged in particularly 'intimate' insider research at the first institution in which I collected data, in the sense that I was well-known to most of my informants for eighteen months before my investigation began, and had freely expressed my opinions on my research topic. By contrast, at the second institution, my research was of a much less 'intimate' nature because my informants had known me less than a year, and I had deliberately chosen not to discuss in any context anything related to my research topic. 
Similarly, a number of teachers were made redundant during the course of my research at the second institution, and, for a time, emotions ran high and feelings of solidarity amongst the faculty appeared to strengthen. As the focus of my research was faculty appraisal, I felt my own position shift somewhat towards the insider end of the continuum at that time.

Likewise, I think I was usually seen as more of an insider when interviewing my fellow teachers than when interviewing members of management, although the power dimension was also affected by my pre-existing rapport with the specific person in question. Thus, for example, interviewing my own line-manager with whom I got on very well felt much the same as interviewing a more senior manager whom I knew socially. Conversely, both of these interviews felt quite different to the one conducted with a middle manager to whom I had never previously spoken.

Finally, there were points in some interviews where particular topics appeared to engender a greater degree of insiderness. At the first institution, for instance, I sometimes sensed a shift in rapport when we discussed the topic of student evaluation of teachers and I revealed that my own score from the previous term had been one of the worst. Such a situation is similar to that experienced by Mullings (1999), in the context of her interviews with mangers of foreign-owned companies in Jamaica. Even within the same interview, on certain issues, such as the difficulties of marketing information processing services, managers appeared willing to view her 'as a temporary insider', whereas, on other issues, such as management-worker relationships, she 'was not welcomed or made to feel an outsider'(1999, p. 349). All of which lends support to Kelleher and Hillier's contention that 'whether respondents 
feel commonality or difference according to gender or cultural identity may fluctuate during the course of one interview' (Kelleher and Hillier, 1996, p. 86).

\section{Part 2: The Double-edged Sword: Pros and Cons of Insiderness}

Merton (1972) identifies two opposing positions, one labelled the Outsider doctrine and the other labelled the Insider doctrine. The Outsider doctrine follows Simmel (1950) in asserting that only the neutral outsider can achieve an objective account of human interaction, because only he or she possesses the appropriate degree of distance and detachment from the subjects of the research. It is the stranger who is able 'to survey conditions with less prejudice' (Simmel, 1950, p. 405), who can 'stand back and abstract material from the research experience' (Burgess, 1984, p. 23), whilst it is the insider, overly-influenced by the customs of his or her group, who remains ignorant, parochially mistaking error for truth (Merton, 1972, p. 30).

By contrast, the Insider doctrine asserts the exact opposite, namely, that the outsider: has a structurally imposed incapacity to comprehend alien groups, statuses, cultures and societies ... [because he or she] ... has neither been socialized in the group nor has engaged in the run of experience that makes up its life, and therefore cannot have the direct, intuitive sensitivity that alone makes empathic understanding possible

(Merton, 1972, p. 15).

Conant (1968) appears to endorse this doctrine fully by claiming that whites can never be as sensitive to the black community as blacks precisely because they are not black. 
Such a position is summarized by Wilson $(1974$, p. 324) to the effect that 'whites are basically incapable of grasping black realities'.

Somewhat less stridently, Oakley (1981) asserts that women interviewing other women enjoy a greater rapport, as a result of their shared experiences, whilst Finch (1984, p. 66) claims 'there is still an additional dimension when the interviewer is a woman because both parties share a subordinate structural position by virtue of their gender'. In a similar way, Ohnuki-Tierney (1984, p. 584) argues that 'native anthropologists are in a far more advantageous position in understanding the emotive dimensions of behavior', whilst Zinn (1979, p. 212) claims that 'minority scholars' are 'less apt to encourage distrust and hostility' and more apt to 'ask questions and gather information others could not'. Likewise, Shah (2004, p. 556) argues that 'a social insider is better positioned as a researcher because of his/her knowledge of the relevant patterns of social interaction required for gaining access and making meaning'.

Merton, himself, considers both doctrines to be fallacies, for the same reason he rejects the insider/outsider dichotomy. Human beings cannot be so easily categorized; individuals within a particular group will not all share exactly the same perceptions, and, therefore, it is not enough to be female (Reay, 1995; Riessman, 1987), black (Beoku-Betts, 1994), or gay (Styles, 1979). The fact that the researcher shares the same gender, ethnicity or sexual orientation with the individuals being researched does not, of itself, make the data any richer. Thus, 'there are no overwhelming advantages to being an insider or an outsider. Each position has advantages and 
disadvantages, though these will take on slightly different weights depending on the particular circumstances and purposes of the research' (Hammersley, 1993, p. 219).

Accordingly, I propose to explore the pros and cons of insiderness in relation to access, intrusiveness, familiarity, and rapport. It is generally presumed that access is more easily granted to the insider researcher and that data collection is less timeconsuming. There is no travelling involved and greater flexibility with regard to interview times. On the other hand, precisely because access is constantly available, it is often harder to tell where research stops and the rest of life begins (Scott, 1985, p. 120). In my own case, data collection from participant-observation quickly became 'all-consuming' because I was contractually required to be on-site eight hours a day, five days a week, without any chance of absenting myself.

Likewise, opinion is divided over the extent to which an insider alters the research process. Hawkins (1990) suggests that a participant-observer who continues to perform his or her normal role within an institution will have more impact on the research than an outsider consultant, whereas Hockey (1993, p. 204) maintains that insiders are able 'to blend into situations, making them less likely to alter the research setting'. Clearly, it partly depends on the position the researcher occupies within the institution. Hawkins was head of the school he was researching, so his suggestion is probably true of his own situation, but less so of mine, since I did not have any direct role in the appraisal system I was researching (other than being appraised as a faculty member).

With regard to the issue of familiarity, insiders will undoubtedly have a better initial 
understanding of the social setting because they know the context; they understand the subtle and diffuse links between situations and events; and they can assess the implications of following particular avenues of enquiry (Griffiths, 1985, p. 211). What is much more debatable is whether or not this heightened familiarity leads to thicker description or greater verisimilitude.

On the one hand, greater familiarity can make insiders more likely to take things for granted, develop myopia, and assume their own perspective is far more widespread than it actually is; the vital significance of the 'unmarked' (Brekhus, 1998) might not be noticed; the 'obvious' question might not be asked (Hockey, 1993, p. 206); the 'sensitive' topic might not be raised (Preedy and Riches, 1988); shared prior experiences might not be explained (Powney and Watts, 1987, p. 186; Kanuha, 2000, p. 442); assumptions might not be challenged (Hockey, 1993, p. 202); seemingly shared norms might not be articulated (Platt, 1981, p. 82); and data might become thinner as a result.

On the other hand, the disorientating and anxiety-provoking effects of culture shock can be avoided (Hockey, 1993, p. 204); and privileged information exploited. As Hannabus (2000, p. 103) notes:

The [insider] researcher knows his / her environment well, knows by instinct what can be done and how far old friendships and favours can be pressed, just when and where to meet up for interviews, what the power structures and the moral mazes and subtexts of the company are and so what taboos to avoid, what shibboleths to mumble and bureaucrats to placate. They are familiar with the organisational 
culture, the routines and the scripts of the workplaces.

In additon, insider researchers usually have considerable credibility and rapport with the subjects of their studies, a fact that may engender a greater level of candour than would otherwise be the case. This is certainly the argument advanced by Hockey (1993, p. 204-205), when he writes:

In effect, because the wider social structure classifies the researcher and informants in a similar or identical fashion, this creates greater confidence between the parties ... One of the results of this trust and exposure to the most intimate of details is that the insider researcher is able to appreciate the full complexity of the social world at hand. The result is a potentially accurate portrayal, rather than a simplistic caricature (Romano, 1968).

Even here, though, the converse could also be argued, to the effect that people may not share certain information with an insider for fear of being judged (Shah, 2004, p. 569). Or else, informants might be more willing to bare their souls to a detached outsider than to someone so intimately bound up with the life of the institution and so enmeshed in its power relations (Dimmock, personal communication, 2005).

In this way, conducting insider research is like wielding a double-edged sword. What insider researchers gain in terms of 'their extensive and intimate knowledge of the culture and taken-for-granted understandings of the actors' may be lost in terms of 'their myopia and their inability to make the familiar strange' (Hawkins, 1990, p. 417). Insider researchers may enjoy easier access and greater rapport, but they also 
have to contend with the fact that their informants have known them that much longer, and have had that much more time to form preconceptions about them and their research. (Hockey, 1993, p. 206).

To summarize the discussion so far, it would seem that definitions of insiderness and outsiderness influence the extent to which we conceive of them as dichotomous or continuous, and this, in turn, influences how far we value one position over the other. In other words, if we define insiderness as sharing a single ascribed status, such as gender, then we are likely to consider the two terms dichotomous, since one cannot be simultaneously both male and female. If, however, we view insiderness in a more pluralistic way (accepting that human beings cannot be classified according to a single ascribed status), then we are likely to consider the two terms as poles of a continuum that is more or less fluid, depending upon the way the end points are conceptualized.

Similarly, the more we conceive of insiderness and outsiderness as an 'either/or' duality, the more we are tempted to judge one as better than the other. Conversely, the more we conceive of them as points on a continuum, the more we are likely to value them both, recognizing their potential strengths and weaknesses, in all manner of contexts.

Part 3: Delicate Dilemmas: Informant Bias, Interview Reciprocity and Research Ethics

Informant Bias - 'Everyone knows what she wants us to say' 
Undoubtedly, 'people's willingness to talk to you, and what people say to you, is influenced by who they think you are' (Drever, 1995, p. 31). In other words, 'Known or expected alignments or loyalties are crucial to the way in which an interviewer is perceived' (Powney and Watts, 1987, p. 40). What is less clear is whether the insider or the outsider is more prone to this kind of informant bias.

Parades (1977) and Zinn (1979) both argue that informants are more likely to present outsiders with a distorted image. 'Sometimes consciously, sometimes unconsciously, the informant may seek to confirm the stereotypes he thinks the Anglo fieldworker has of him rather than expressing his own attitudes and opinions' (Parades, 1977, p. 29). This certainly seems to have been the case with the renowned anthropologist, Margaret Mead. According to Shore (1982), the first Samoans to read Coming of Age in Samoa, (Mead, 1929), insisted the author had lied. Later, according to Freeman (1988, p. 289), they came to the conclusion that her informants had been deliberately telling tall tales. In other words, when Mead, 'a liberated young American' persisted 'in this unprecedented probing of a highly embarrassing topic, it is likely that these girls resorted ... to ... regaling their inquisitor with counterfeit tales of casual love under the palm trees' (Freeman, 1988, p. 289).

On the other hand, it could be argued that the potential for distortion is usually greater within the context of insider research, for two reasons. Firstly, as Preedy and Riches (1988, p. 221) note, respondents may face 'problems of tempering the truth in the knowledge that fruitful professional relationships ... [have] ... to continue after the research had been completed'. In other words, pragmatism may outweigh candour. Similarly, preconceptions may colour accounts, because so much more is already 
known (or thought to be known) about the interviewer's opinions. Whilst the outsider is 'a man without a history' (Schutz, 1964, p. 34), the insider cannot escape his or her past.

At the first site, I had been very vocal on the subject of faculty appraisal for 18 months prior to beginning my research. It was a subject I felt strongly about, and one I discussed frequently with colleagues. Most of my interviewees already knew how I viewed appraisal, and this knowledge certainly affected the information they chose to give me, although precisely how I can never know. At the second site, in an attempt to minimize this kind of influence, I made a conscious effort not to voice my opinions about faculty appraisal, in any context, until after my research had been written up. As a result, my informants were not aware of my own particular stance on this issue, although, of course, they may still have tailored their responses in any number of other ways, for any number of other reasons.

\section{Interview Reciprocity - 'I'll show you mine, if you show me yours'}

By conducting insider research with the same focus, approach and tools, at two very similar sites, I was able to experiment with differing levels of intimacy. As we have seen, informants at the first site were far more aware of my perspective than informants at the second site, before the interviews even began. This was also the case, during the interviews themselves, in the sense that the 19 interviews I conducted at the first site were generally far more reciprocal than the $19 \mathrm{I}$ conducted at the second site. In the first phase of my research, I often commented upon what interviewees said and added my own stories in the belief that this would strengthen 
our rapport and encourage my informants to contribute further. The following two transcript extracts are typical of my interviewing style at the first site:

\section{Extract One: Being observed as part of the appraisal process:}

Informant: The first visit to the classroom, there was absolutely zero observation of any classroom teaching.

Researcher (me): What do you mean?

Informant: Well, in that classroom visit, because it was ... the end of the semester, [a colleague] and I were doing team-teaching, and ..., and it happened to be during presentation week. And so, basically, [the colleague] and I came in, sat down and the students gave their presentations, and at the end, the appraiser just said very nice, you're doing a great job.

Researcher (me): Yeah, that's exactly what happened to me this semester. [My supervisor] came and watched [my teaching partner] and I sit in on presentations.

\section{Extract Two: How management is perceived:}

Researcher (me): So would you care to expand on what this means for your opinion of those people in [the administration block]?

Informant: I think that like so many other things here, they're way over their heads. I mean, they have a lot of good qualified instructors and professors. And they don't 
know how to use them. They don't know how to take advantage of their resources. And it's just going to continue.

Researcher (me): Well, then, how do you feel about being asked to do the appraisal system? You say that they're not taking advantage of the highly qualified faculty that they have. This suggests that you feel, maybe, slightly insulted? (I don't want to put words in your mouth) by the appraisal system.

Informant: Definitely insulted, from the very beginning. I mean, insulted, that ...I should write a statement of teaching philosophy, as should the other 200 instructors, when everyone knows they're not going to read them ...

In the first extract, I share my own experience of classroom observation, which mirrors that of my informant; in the second extract, despite my desire not to, I do indeed put the word "insulted" into my informant's mouth. How far either of my own two contributions are furthering or hindering the joint construction of meaning is clearly a moot point.

Some authors (such as Brenner, 1981) argue in favour of a highly structured interview approach, insisting that the interviewer stick to the exact wording and order of each question in an attempt to achieve a standardized prompt. This approach also has the advantage of ensuring all the questions get asked, and of facilitating very close 'question-by-question' data analysis. However, it can feel constricting for both parties, and a semi-structured approach is usually preferred, although few authors 
define exactly how much digression from the standardized prompt is considered desirable. Smith (1995, p. 15), for example, acknowledges that a more interactive / conversational approach may yield more extensive data, and therefore accepts a certain amount of digression and reordering of questions in the interests of establishing rapport.

All the same, many authors still caution interviewers very strongly against revealing any of their own thoughts. Holstein and Gubrium (2003, p. 13) suggest that 'Interviewers are generally expected to keep their 'selves' out of the interview process. Neutrality is the byword'. According to Powney and Watts (1987, p. 42), the interviewer who reveals his or her personal viewpoint distracts the interviewee, encourages acquiescence, and even sets up a self-fulfiling prophecy. Interviewers who share experiences with informants minimize 'the 'bracketing' that is essential to construct the meaning of participants in phenomenology and reduces information shared by informants in case studies and ethnography (Cresswell, 1996, p. 133).

Likewise, Platt (1981, p. 77) writes of the need to resist the temptation: ... to contribute discreditable stories about oneself in anticipation and legitimation of return, to appear to get the point quickly without requiring explicit statements, and to treat the interview situation as one no different from other conversations and so contribute one's own quota of gossip and comment to the discussion.

On the other hand, Porter (1984) felt a pastoral obligation to answer questions she was asked during her interviews with postgraduate students, so long at this did not 
compromise the confidentiality of other informants. "There was a commitment to the students which would not allow total detachment from their interests" (Porter, 1984, p. 157).

Similarly, Hawkins (1990, p. 417) felt that the minimal responses used by ethnographers to elicit further information could be misinterpreted as a lack of interest. He also found that sometimes he had to give information in exchange for what he wanted from informants (Hawkins, 1990, p. 416).

Taking this a stage further, both Oakley (1981) and Logan (1984) argue that interviewers ought not to withhold their own views or resist friendship and involvement because sharing experiences and attitudes helps to develop trust. Likewise, Griffin (1985) recounts how the young women in her study often turned her questions around by asking how she, herself, felt about leaving school and getting her first job. 'A positivist approach might treat these questions as irrelevant or unwanted intrusions, or as potential sources of "data contamination" but I saw them as part of the reciprocal nature of the research process' (Griffin, 1985, p. 102).

Ellis and Berger (2003, p. 471) write of a similar situation in which 'The interviewing process becomes less a conduit of information from informants to researchers that represents how things are, and more a sea swell of meaning making in which researchers connect their own experiences to those of others and provide stories that open up conversations about how we live and cope'.

Clearly, interviews are influenced not only by the perspectives of the people involved, 
but also by the research focus, paradigm and approach. For example, large-scale surveys, within a quantitative paradigm, are likely to use structured or discrete point interviews as a tool for eliciting pre-determined information whereas small-scale case studies, within a qualitative paradigm, are likely to use unstructured or in-depth interviews as a means of constructing participative knowledge (Shah, 2004, p. 552).

I argued earlier that it is more helpful to conceive of insiderness and outsiderness as a continuum with many dimensions rather than as a single dichotomy. In the same way, interview schedules can be considered more or less structured, depending upon the research purpose, scale and methodology, as well the perceptions of both the interviewee and interviewer. For this reason, a different degree of reciprocity will be achieved within each interview.

Generally, at my first site, the interviews were highly interactive, and it could be argued that I led informants into saying things they did not intend to say. Indeed, an academic colleague from a different institution who read two of my transcripts (with permission) clearly thought this was exactly what I had done.

In order to ensure that my data could not be dismissed in this way, I thereafter tried to limit my own contributions to the conversation, and found that, if I waited long enough and smiled encouragingly enough, people most often completed their sentences with the very phrases I had been itching to supply during the intervening pause. Ball (1994, p. 181) discusses the possibility that 'respondents may find themselves manipulated into saying more than they intend'. I, myself, remain undecided about exactly how far a naïve (or, perhaps, very skilful) interviewer really 
can make people say things they do not actually mean, or reveal things they never intended to let slip. Still, I have come round to the idea that it is best, as a researcher, to avoid this potential accusation by adopting an interviewing style that is less gregarious than my natural disposition.

\section{Research Ethics - 'Nowhere to hide'.}

All researchers face a variety of ethical dilemmas, but, for the insider researcher, two of them take on particular significance. First, there is the issue of what to tell colleagues, both before and after they participate in the research. Powney and Watts (1987, p. 147) argue that research benefits from interviewees being 'fully informed from the start of what the researchers and the interviewees are trying to establish'. More realistically, Bulmer (1982, p. 243) contends that 'all field research involves giving misinformation, less than full information or even mild deceit to some extent'. Researchers need to avoid 'contaminating' their study 'by informing subjects too specifically about the research questions to be studied' (Silverman, 2000, p. 200). For Platt (1981, p. 80), the dilemma is particularly acute when interviewing one's peers:

Thus, it seems offensive not to give some honest and reasonably full account of the rationale and purpose of one's study to such respondents [who are equals] and the account cannot be one that is intellectually condescending. However, it is difficult to do this without inviting discussion of the study rather than getting on with the interview, and without providing so much information that it may bias the course of the interview. 
When I started researching faculty appraisal at the first site, many people were already aware of my perspective on the subject and knew this was the focus of my research. When I changed jobs half-way through the study, I made a conscious decision not to reveal my opinions in public, and not to specify exactly what I was researching. If people asked, I merely told them I was looking at an aspect of 'education management', and this was the phrase I used when approaching people for interview, preferring to introduce the word 'appraisal' only at the start of the actual recording.

I was even more circumspect about reporting my findings. Edwards and Furlong (1985, p. 33) maintain that 'The major criterion of external validity is still the idea of presenting the researcher's account back to the researched. To be valid, an account must have convergence with the experience of the researched'. Such member checking is believed to increase the trustworthiness of qualitative research. Unfortunately, such a belief fails to take account of the fact that the perspectives of individual informants may be ambivalent at any given moment, may change over time, and may contradict one another to such an extent that consensus is impossible.

With regard to respondent validation, Drever (1995, p. 64) argues that 'rather than commenting on the accuracy of your summary, they [the informants] are liable to want to expand and explain their answers, thereby introducing their own subjective bias into the interview record'. Likewise, Silverman (2000, p. 125) contends that informants' responses are not so much factual statements describing their experience of reality, as contextually-embedded narratives with a rhetorical force. In other words, 'Practitioners' accounts of their reality are themselves constructions of reality and not reality itself' (Anderson and Jones, 2000, p. 44). The same person can have multiple 
understandings of reality, depending on the situation, and their verbal descriptions of these various understandings (be they 'genuine' or consciously contrived) will be different at different times and with different people. Accordingly, validation is 'a flawed method' (Silverman, 2000, p. 177) because it does not verify data; it merely increases them.

Similarly, Silverman (1993) argues that because accounts are context-bound, they cannot be verified by generating data from multiple sources. Triangulation seems to 'assume that the truth exists only in the space where multiple Venn diagrams converge' whereas 'some of the truth may be found in the places in the diagram where the circles do not converge' (Sofaer, 1999. p. 4). This was partly why I chose not to return transcripts for validation, nor present my findings to informants.

More importantly, I was concerned that confidentiality might be compromised. In an attempt to encourage candour, I had assured participants that I did not intend to report my findings to the senior management team, a promise I reiterated on the consent form each informant signed. It is impossible to tell what effect this promise may have had, but a number of my informants made reference to the fact they were telling me things in strictest confidence, including one who said she thought she would be "removed from the college immediately" if management heard what she had told me. Before I began my research, I took the view that little would be gained from presenting my findings to any group within either institution, and much might be lost, both personally and professionally, for researcher and informant alike. This continues to be my view, although now that I have moved thousands of miles from both institutions, I am a little less anxious about allowing the wider research community to 
critique my findings. Were I still working at either of the two institutions in question, I would have kept certain aspects of my research under wraps for a little while longer.

A second ethical dilemma for the insider researcher concerns the use of 'incidental' data. Griffiths (1985, p. 210) describes how she chose not to use material from informal staffroom chats, or meetings with restricted access because the collection of these data had not been negotiated: 'To release such data would be a betrayal of trust and an abuse of access. Herein probably lies another key to the research position, and that is the need for an understanding of the difference between research and voyeurism'. Campbell (2002, p. 41) felt somewhat the same, preferring to use only data from direct personal conversations, rather than anything he overheard by chance.

However, like Pollard (1985) and Scott (1985), I decided against such an approach, partly because, unlike Campbell, I did not hold any position of responsibility in either of the institutions I researched, and partly because, as previously discussed, I had no intention of presenting my findings to anyone at my place of work.

\section{Conclusion}

In this paper, I have explored the concept of insiderness and argued that the extent to which any researcher is considered an insider or an outsider is not dependent upon a single inherent characteristic, such as gender or ethnicity. Insiderness depends, rather, upon the intersection of many different characteristics, some inherent and some not. The researcher's relationship with the researched is not static, but fluctuates constantly, shifting back and forth along a continuum of possibilities, from one 
moment to the next, from one location to the next, from one interaction to the next, and even from one discussion topic to the next.

I have also explored the apparent advantages and disadvantages of insider research, claiming that insiders, on the one hand, often enjoy freer access, stronger rapport, and a deeper, more readily-available frame of shared reference with which to interpret the data they collect, but, on the other, have to contend with their own pre-conceptions, and those their informants have formed about them as a result of their shared history.

I have discussed three of the dilemmas I faced, concerning informant bias, interview reciprocity and research ethics, and, based on my experience, I have suggested that, although informants will inevitably form preconceptions about any researcher, it is usually better for insider researchers not to publicize their own opinions about their research topic, nor contribute their own stories in interviews. I, myself, am not convinced that researchers who reveal their own stance automatically contaminate their data, but this is a highly debateable point. For this reason, it would seem advisable not to lay oneself open to such an accusation, if it can be avoided.

I would like to have ended this paper with a clear statement of exactly how far and in what ways different degrees of insiderness affect the collection and interpretation of data in educational contexts. Unfortunately, I cannot do this at the present time because relatively little has been published about this topic, and considerably more research is needed before any kind of 'fuzzy generalisations' (Bassey, 1999, p. 62) can be made. Even then, I suspect that the variables involved will prove just too numerous and too fluid to fit into a tidy taxonomy. 
Hockey (1993, p. 200) suggests that being an insider 'may potentially influence the whole research process - site selection, method of sampling, documentary analysis, observation techniques and the way meaning is constructed from the field data' Likewise, Griffith (1998, p. 362) claims that an insider produces 'a different knowledge' from an outsider, although she does not elaborate on exactly what this means. By contrast, Anderson and Jones (2000, p. 433), after analyzing 6 dissertations and 50 abstracts written by 'administrator-researchers', come to the conclusion that 'Many of the administrators who did studies within their own settings did not perceive their research as different from outsider research'.

My own research experience falls somewhere between these two extremes. On the one hand, I did perceive my research as different from outsider research, and I did think the research process was somewhat different at the two sites, partly because I felt a greater level of intimacy at the first site, and partly because I so consciously altered my interviewing style at the second site. On the other hand, the data I collected from the two institutions were remarkably alike, in both content and form. The substantive findings from each case study were almost identical, and informants at both places made similar comments about the data collection process in terms of confidentiality and levels of candour. So, although I perceived a difference in my respective positioning in each institution, the participants of my research did not seem to have been affected by it, in terms of their responses. Perhaps what was the same in terms of my gender, ethnicity, personality, job description, and standing in the organisational hierarchy outweighed what was different in terms of length of prior acquaintance and style of interviewing. 
Thus, I remain unsure about the extent to which different degrees of insiderness (or outsiderness) affect research processes and findings. As Labaree (2002, p. 118) notes, 'the challenge of unmarked insiderness within the professions is an issue in need of further analysis', and more research is called for. Such research would obviously encompass teachers like myself studying their peers and those above them in the organisational hierarchy, but it would also need to look at the dynamics of middle and senior academic managers studying not only their peers and those above them, but also those below them whom they line-manage. Within this paper, I have discussed power relations only briefly, because I do not feel they had a major impact upon my research, since I was 'just' a faculty member at each institution. In effect, I occupied the bottom rung of the ladder. Had I occupied any higher position, power relations would certainly have had more of an impact. Hence, there seems to me to be a pressing need to investigate not only insider research by teachers in general, but especially insider research by academic managers occupying a broad range of positions within the power hierarchies of their places of work. If this were done, the ever-increasing number of educationalists researching the leadership and management of their own institutions might be better prepared to meet the unique challenges they face.

\section{Acknowledgements}

I would like to thank Ann Briggs, and especially David Hellawell, Bernard Barker and Clive Dimmock for their detailed feedback on two earlier drafts of this paper. I would also like to thank the two anonymous referees for their comments.

\section{References}


Aguilar, J. L. (1981) Insider research: an ethnography of a debate, in: D. A. Messerschmidt (Ed) Anthropologists at home in North America (Cambridge, Cambridge University Press).

Anderson, G. L. and Jones, F. (2000) Knowledge generation in educational administration from the inside out: the promise and perils of site-based, administrator research, Educational Administration Quarterly, 36 (3), 428-464.

Ball, S. (1994) Political interviews and the politics of interviewing, in: G. Walford (Ed) Researching the powerful in education (London, UCL press).

Bassey, M. (1999) Case study research in educational settings (Buckingham, Open University Press).

Beoku-Betts, J. (1994) When black is not enough: doing field research among Gullah Women, NWSA Journal, 6 (3), 413-433.

Brekhus, W. (1998) A sociology of the unmarked: redirecting our focus, Sociological Theory, 16 (1), 34-51

Brenner, M. (1981) Patterns of social structure in the research interview, in: M. Brenner (Ed) Social method and social life (London, Academic Press Limited).

Bulmer, M. (1982) When is disguise justified? Alternatives to covert participant observation, Qualitative Sociology, 5 (Summer), 269-85.

Burgess, R. G. (Ed) (1984) In the field: an introduction to field research (London, Unwin Hyman).

Campbell, A. (2002) Implementing appraisal: a case study of the implementation of an appraisal system, Unpublished Ed.D. thesis, (Milton Keynes, The Open University).

Carr, W. and Kemmis, S. (1983) Becoming critical: knowing through action research (Victoria, Deakin University Press).

Carter, J. (2004) Research notes: reflections on interviewing across the ethnic divide, International Journal of Social Research Methodology, 7(4), 345-353.

Cassell, C. (2005) Creating the interviewer: identity work in the management research process, Qualitative Research, 5(2), 167-179.

Christensen, D. H. and Dahl, C. M. (1997) Rethinking research dichotomies, Family and Consumer Sciences Research Journal, 25(3), 269-85.

Conant, R. W. (1968) Black power in urban America, Library Journal 93(15), 1963 1967.

Cresswell, J. W. (1996) Qualitative inquiry and research design: choosing among five traditions (California, Sage Publications Incorporated). 
Deutsch, C. P. (1981) The behavioral scientist: insider and outsider, Journal of Social Issues, 37(2), 172-191.

DeVault, M. L. (1996) Talking back to sociology; distinctive contributions of feminist methodology, Annual Review of Sociology, 22, 29-50.

Drever, E. (1995) Using semi-structured interviews in small-scale research (Edinburgh, The Scottish Council for Research in Education).

Edwards, A. D. and Furlong, V. J. (1985) Ethnography and theory construction in educational research, in: R. Burgess (Ed) Field methods in the study of education (Lewes, Falmer Press).

Ellis, C. and Berger, L. (2003) Their story / my story / our story, in: J. Holstein and J. Gubrium, (Eds) Inside interviewing; new lenses, new concerns, (Thousand Oaks, Sage).

Finch, J. (1984) 'It's great to have someone to talk to': the ethics and politics of interviewing women, in: C. Bell and H. Roberts (Eds) Social researching (London, Routledge, Kegan Paul).

Freeman, D. (1983) Margaret Mead and Samoa (Cambridge, Harvard University Press).

Griffin, C. (1985) Qualitative methods and cultural analysis, in: R. Burgess (Ed) Field methods in the study of education (Lewes, Falmer Press).

Griffith, A. I. (1998) Insider / outsider: epistemological privilege and mothering work, Human Studies, 21, 361-376.

Griffiths, G. (1985) Doubts, dilemmas and diary-keeping: some reflections on teacher-based research, in: $\mathrm{R}$. Burgess (Ed) Issues in educational research: qualitative methods (London, The Falmer Press).

Hammersley, M. (1993) On the teacher as researcher, in: M. Hammersley (Ed) Educational research: volume one; current issues (London, Paul Chapman Publishing Limited/The Open University).

Hannabus, S. (2000) Being there: ethnographic research and autobiography, Library Management, 21 (2), 99-106.

Hawkins, B. S. R. (1990) The management of staff development in a contracting education service Unpublished Ph.D. thesis, (Birmingham, Birmingham Polytechnic).

Hockey, J. (1993) Research methods - researching peers and familiar settings, Research Papers in Education, 8 (2), 199-225.

Holstein, J. and Gubrium, J. (Eds) (2003) Inside interviewing; new lenses, new concerns, (Thousand Oaks, Sage). 
Kanuha, V. K. (2000) "Being" native versus "going native"; conducting social work research as an insider, Social Work, 45(5) 439-447.

Kelleher, D. and Hillier (1996) S. (Eds) Researching cultural differences in health (London, Routledge).

Kemmis, S. (1993) Action research, in: M. Hammersley (Ed) Educational research: current issues (London, Paul Chapman Publishing Limited/The Open University).

Labaree, R. V. (2002) The risk of 'going observationalist': negotiating the hidden dilemmas of being an insider participant observer, Qualitiative Research, 2(1), 97 122.

Logan, T. (1984) Learning through interviewing, in: J. Schoslak and T. Logan (Eds) Pupil Perspectives (London, Croom Helm).

Lomax, P. (2002) Action research, in: M. Coleman and A. Briggs (Eds) Research Methods in Educational Leadership and Management (London, Sage Publications).

Malinowski, B. (1922) Argonauts of the Western Pacific (London, Routledge and Kegan Paul).

Mead, M. (1929) Coming of Age in Somoa (New York, Jonathon Cape).

Merton, R. (1972) Insiders and outsiders; a chapter in the sociology of knowledge, American Journal of Sociology, 78(July), 9-47.

Mullings, B. (1999) Insider or outsider: both or neither: some dilemmas of interviewing in a cross-cultural setting, Geoforum, 39(4), 337-350.

Narayan, K. (1993) How native is a "native" anthropologist? American Anthropologist, 95(3), 671-686.

Oakley, A. (1981) Interviewing women, in: H. Roberts (Ed) Doing Feminist Research (London, Routledge and Kegan Paul).

Ohnuki-Tierney, E. (1984) "Native" anthropologists, American Ethnologist, 11(3), 584-586.

Olson, D.H. (1977) Insiders' and outsiders' views of relationships: research studies, In: G. Levinger and H. L. Rausch (Eds) Close relationships: perspectives on the meaning of intimacy (Amhurst, University of Massachusettes Press).

Parades, A. (1977) On ethnographic work among minority groups: a folklorist's perspectrive, New Scholar, 6, 1-53.

Platt, J. (1981) On interviewing one's peers, The British Journal of Sociology, 32 (1), 75-91. 
Pollard, A. (1985) Opportunities and difficulties of a teacher-ethnographer: a personal account, in: R. Burgess (Ed) Field methods in the study of education (Lewes, Falmer Press).

Porter, M. (1984) The modification of method in researching postgraduate education' in R. Burgess (Ed) (1984) The research process in educational settings: ten case studies (Lewes, The Falmer Press).

Powney, J. and Watts, M. (1987) Interviewing in educational research (London, Routledge and Kegan Paul Limited).

Preedy, M. and Riches, C. (1988) Practitioner research in school management: an analysis of research studies undertaken for an Open University course, in: J. Nias and S. Groundwater-Smith (Eds) The enquiring teacher: supporting and sustaining teacher research (Lewes, Falmer Press).

Reay, D. (1995) Feminist research: the fallacy of easy access, Women's Studies International Forum, 18 (March-April), 205-213.

Reissman, C. K. (1987) When gender is not enough: women interviewing women, Gender and Society, 1(June), 172-207

Schon, D. (1983) The reflective practitioner (New York, Basic Books).

Schulz, A. (1971) The stranger: an essay in social psychology, in: B. R. Cosin, I. R. Dale, G. M. Esland and D. F. Swift (Eds) School and society (London, Routledge and Kegan Paul in association with The Open University Press).

Scott, S. (1985) Working through the contradictions in researching postgraduate education, in: R. Burgess (Ed) Field methods in the study of education (Lewes, Falmer Press).

Shah, S. (2004) The researcher / interviewer in intercultural context: a social intruder! British Educational Research Journal, 30(4), 549-575.

Shore, B. (1982) Sexuality and gender in Somoa: conceptions and missed conceptions, in: S. Ortner and H. Whitehead (Eds) Sexual Meanings (Cambridge, Cambridge University Press).

Silverman, D. (1993) Interpreting qualitative data: methods, for analysing talk, text and interaction (London, Sage Publications).

Silverman, D. (2000) Doing qualitative research: a practical handbook (London, Sage Publications).

Simmel, G. (1950) The sociology of Georg Simmel, (New York, Free Press).

Smith, J. A. (1995) Semi-structured interviews and qualitative analysis, in: J. A. Smith, R. Harre and L, Van Langenhove (Eds) Rethinking methods in psychology (London, Sage Publications Limited). 
Sofaer, S. (1999) Qualitative methods: What are they and why use them? Health Services Research, 34 (5), 1101-1118.

Styles, J. (1979) Outsider / insider: researching gay baths, Urban Life: A Journal of ethnographic research, 8(July), 135-152.

Surra, C. A. and Ridley, C. A. (1991) Multiple perspectives on interaction: participants, peers and observers, in: B. M. Montgomery and S. Duck (Eds) Studying international interaction, (New York, Guildford Press).

Wilson, W. J. (1974) The new black sociology: reflections on the "insiders" and "outsiders" controversy', in: J. E. Blackwell and M. Janowitz (Eds) Black sociologists: historical and contemporary perspectives (Chicago, University of Chicago Press).

Zinn, M. B. (1979) Field research in minority communities: ethical methodological and political observations by an insider, Social Problems, 27(2), 209-219. 